\title{
Chapter 15 \\ A Change in the Ice Regime: Polar Code Implementation in Canada
}

\author{
Drummond Fraser
}

\begin{abstract}
In 2017 Canada implemented the Polar Code into domestic legislation, marking the most significant update to Arctic shipping safety and pollution prevention in over 20 years. While much has been written about the events leading to its creation, this chapter will instead focus on the steps taken by Canada after Polar Code adoption, in particular the domestic considerations that culminated with the creation of the Arctic Shipping Safety and Pollution Prevention Regulations. Changes made by Canada to certain Polar Code provisions during implementation are highlighted, as are ongoing efforts at the International Maritime Organization to further advance standards for ships operating in polar waters.
\end{abstract}

Keywords Arctic · Antarctic · Equipment - Guidelines · International Maritime Organization $\cdot$ Marine pollution prevention $\cdot$ Operations $\cdot$ Polar Code $\cdot$ Regulations $\cdot$ Safety $\cdot$ Sea ice $\cdot$ Shipping $\cdot$ Training $\cdot$ Vessel design

\subsection{Introduction}

On 1 January 2017, the International Code for Ships Operating in Polar Waters (the Polar Code) entered into force internationally. The product of years of negotiations at the International Maritime Organization (IMO), the primary objective of the Polar Code is to address the unique hazards confronted by ships operating in the Arctic and Antarctic through the introduction of a variety of safety and pollution prevention measures, including those related to design and equipment, operations, crew training, and the protection of the marine environment.

Canada played an instrumental role in the development of the Polar Code, leveraging over 40 years of experience in the oversight of Arctic shipping. As a result of

D. Fraser $(\bowtie)$

Marine Safety and Security, Transport Canada, Ottawa, Canada

e-mail: drummond.fraser@tc.gc.ca 
this active engagement, the content of the Polar Code—-from the hazards addressed, to how a ship should operate in ice, to the restrictions placed on certain dischargesis influenced significantly by Canadian safety and environmental standards.

The Polar Code is not a new IMO treaty or convention. Rather, it is a technical code implemented through amendments to the existing International Convention for the Safety of Life at Sea, 1974 (SOLAS 1974) and the International Convention for the Prevention of Pollution from Ships, 1973/78 (MARPOL) by way of tacit acceptance (Polar Code 2014/2015). Under this process, states that are signatories to these conventions automatically become bound by amendments unless an intention to object is formally submitted to the Secretary-General of the IMO.

Following the adoption of the final text of the Polar Code, Canada initiated a technical review of its content and the enabling amendments to both SOLAS and MARPOL. A comparative analysis was also undertaken to determine the extent to which these newly adopted international measures differed from the prevailing domestic ones, and whether any reasonable grounds existed to warrant formal objection. The results of this technical review are highlighted below, along with the various regulatory incorporation options and unique amendments considered by Canada to make the Polar Code applicable domestically. The chapter concludes by noting the ongoing work at the IMO to develop guidance material to supplement the Polar Code's goal-based safety standards, as well as its possible expansion to others types of vessels not originally considered (e.g., fishing vessels and pleasure craft).

\subsection{Technical Review of the Polar Code}

Drawing on operational and technical expertise from across the Government of Canada, every goal, functional requirement, and regulation contained in Part I-A (Safety Measures), and every prescriptive regulation contained in Part II-A (Pollution Prevention Measures) of the Polar Code, as well as the entirety of SOLAS Chapter XIV and the related amendments to MARPOL Annexes I, II, IV, and V, were subject to review and analysis. To facilitate this exercise, a concordance table was developed whereby the dissected and itemized contents of the Polar Code were individually identified as being either "higher" (e.g., more stringent), "lower" (e.g., less stringent), or on par with the closest equivalent standard across the suite of acts, regulations, and guidance material that constitute Canada's Arctic shipping regulatory regime. Any specific considerations unique to Canada and not directly captured by the adopted text of the Polar Code (e.g., Canadian ice class notations, ice navigator requirements) were highlighted and assigned a provisional location for regulatory incorporation. Moreover, to assist with the overall tacit acceptance review, a recommendation on whether or not an objection should be made to each provision was also indicated.

The safety portions of the Polar Code are established through the addition of a completely new chapter to SOLAS—Chapter XIV (Safety Measures for Ships Operating in Polar Waters). Comprised of four regulations that contain universal definitions (e.g., Arctic waters, Antarctic area), that set out application and 
certification criteria, and that make allowances for the use of alternate design arrangements, this chapter provides an overarching framework under which the specific safety features of the Polar Code are organized.

Regulation 2 of Chapter XIV contains language concerning the rights and obligations of states under international law. This is particularly noteworthy for Canada as its inclusion guarantees that the contents of the Polar Code established through SOLAS do not in any way prejudice or infringe upon rights enshrined elsewhere, in particular Article 234 of the United Nations Convention on the Law of the Sea (UNCLOS 1982), which allows coastal states the ability to adopt and enforce laws for the prevention of pollution from ships operating in ice-covered areas:

Coastal States have the right to adopt and enforce non-discriminatory laws and regulations
for the prevention, reduction and control of marine pollution from vessels in ice-covered
areas within the limits of the exclusive economic zone, where particularly severe climatic
conditions and the presence of ice covering such areas for most of the year create obstruc-
tions or exceptional hazards to navigation, and pollution of the marine environment could
cause major harm to or irreversible disturbance of the ecological balance. Such laws and
regulations shall have due regard to navigation and the protection and preservation of the
marine environment based on the best available scientific evidence.

Canada's Arctic Waters Pollution Prevention Act (AWPPA 1970) and Northern Canada Vessel Traffic Services Zone Regulations (NORDREG 2010) were both enacted to protect the Arctic marine environment via more stringent pollution prevention measures and are directly linked to Article 234.

It is worth noting that at the time of its accession to the 1978 Protocol to MARPOL, Canada deposited a declaration to the IMO asserting its "right in accordance with international law to adopt and enforce special non-discrimination laws and regulations for the prevention, reduction and control of marine pollution from vessels in ice-covered arctic waters ... within or adjacent to Canada" (IMO 1992). This declaration was also based on Article 234 of UNCLOS and was later reaffirmed when Canada formally accepted the Polar Code-related amendments to MARPOL in 2018.

After careful review, all four regulations contained in SOLAS Chapter XIV were accepted. Similarly, with respect to the various amendments to regulations contained in MARPOL Annexes I, II, IV, and V that consequentially amend existing text to include appropriate references to Part II-A of the Polar Code and that add new Polar Code-specific chapters to each of the identified annexes, no reasonable grounds to object were identified.

As for the mandatory text of the Polar Code itself - that is, the 12 safety chapters, five pollution prevention chapters, and the related introductory text (all enabled by the aforementioned SOLAS and MARPOL amendments) - no objections to its content were raised upon the completion of the technical review. Indeed, with a precautionary and pollution prevention-focused domestic regime for Arctic shipping in place since the early 1970s, much of this content was already applicable to ships operating in Canada. 


\subsection{Regulatory Incorporation Options}

Despite the absence of any formal objection, certain administrative concerns were identified with respect to the length of time required by Canada to discharge its international law obligations under both conventions through the introduction of new or the update of existing regulations by the 1 January 2017 international entry into force date.

In response to these concerns, several regulatory incorporation options were considered. The option ultimately chosen was to use IMO mechanisms made available under both conventions to delay entry into force, thus formally providing Canada with additional time to complete its necessary domestic processes. Under SOLAS, contracting parties have up to 1 year from the international entry into force date to delay, meaning that Canadian regulations concerning the safety provisions of the Polar Code would need to be in force no later than 1 January 2018. No specific time limit exists under the MARPOL Convention concerning delayed entry into force.

Accordingly, a formal process was soon set in motion authorizing the Government of Canada to accept amendments adding Chapter XIV to SOLAS, adopted by the Maritime Safety Committee (MSC) of the IMO on 21 November 2014, and the amendments to Annexes I, II, IV, and V of MARPOL, adopted by the Marine Environment Protection Committee (MEPC) of the IMO on 15 May 2015. In addition, the High Commission of Canada in the United Kingdom sent notice to the Secretary-General of the IMO, in accordance with Article VIII(b)(vii)(2) of SOLAS, exempting Canada for a period of not more than 1 year from giving effect to the amendments that introduce the provisions of the Polar Code into that Convention on account of national procedural requirements. The High Commission also notified the Secretary-General that, in accordance with Article 16(2)(f)(ii) of MARPOL, and also due to national procedural requirements, Canada's express approval would be necessary before the amendments to that treaty entered into force.

\subsection{The Arctic Shipping Safety and Pollution Prevention Regulations}

Subsequent to landing on the delayed entry into force approach, and after much internal consultation and review, it was agreed that a single regulation that incorporated the Polar Code into Canadian law be pursued, and that this was both feasible and likely to be in place during 2017, thereby meeting the 1 January 2018 delayed implementation deadline. The single regulation approach was chosen over the more piecemeal alternative that would involve making amendments to a variety of individual regulations subject to their own unique and potentially lengthy regulatory timelines.

Canada therefore proposed to capture the Polar Code domestically through the creation of a completely new regulation: the Arctic Shipping Safety and Pollution 
Prevention Regulations (ASSPPR 2017). At the same time it would also make a variety of consequential amendments to avoid conflict or duplication with other regulations relevant to Arctic operations, in particular a full repeal of the Arctic Shipping Pollution Prevention Regulations (ASPPR 2006).

Central to incorporating the Polar Code domestically via the ASSPPR was ensuring that existing levels of safety and pollution prevention applicable to ships operating in Canadian Arctic waters were not eroded, and that only those international standards adopted by the IMO that further strengthened safety and pollution prevention would be introduced. Accordingly, Canada proposed that this new regulation fully incorporate by reference the safety provisions (Part I-A) of the Polar Code and that the environmental provisions be drafted so as to take into consideration existing discharge prohibitions made under the AWPPA. Additional Canadian modifications not contained within the adopted text of the Polar Code were also introduced.

The concordance table developed during the previous technical review served as a guiding document in the drafting of the ASSPPR, ultimately informing the extent to which the Polar Code should be replicated in full and the degree to which Canadaspecific amendments should be introduced. This review was complemented by further consultations with key stakeholders across all levels of government, industry, academia, and the non-governmental organization community, the views and opinions of which were critical in shaping the final regulatory draft.

Without context or familiarity with the interrelationship between the ASSPPR and other pieces of Canadian legislation, reading the regulations in isolation can be limiting. Therefore, to facilitate a greater understanding of its application and intent, certain illustrative features of the ASSPPR and the chapters of the Polar Code incorporated by reference are highlighted below.

\subsubsection{General Provisions}

The general provisions section of the ASSPPR contains terminology applicable throughout both the safety and pollution prevention parts of the regulation, as well as definitions not contained within the adopted text of the Polar Code though required to be included in order to reflect certain Canadian modifications. For example, to make the distinction between the application of the regulations to Canadian flagged ships outside Canadian Arctic waters (though still within polar waters), and all ships within Canadian Arctic waters, the term "shipping safety control zone" is used to refer to the latter. 


\subsubsection{Safety Measures}

The entirety of the introduction and Part I-A of the Polar Code is incorporated by reference, meaning that rather than replicate this content in full in the body of a regulation, the ASSPPR instead simply indicates that applicable ships must conform fully to the requirements of SOLAS Chapter XIV. In turn, SOLAS Chapter XIV makes separate reference to the introduction and the 12 safety-related chapters of the Polar Code.

\subsubsection{Introduction}

The introduction contains the primary goal of the Polar Code, definitions to be used in both the safety and pollution prevention sections, a list of hazards to consider during polar operations, and a brief description of the document's structure. The introduction provides definitions that establish context for the Polar Code, many of which are similar to definitions used in the Canadian regime prior to incorporation.

\subsubsection{General}

Chapter 1 provides the overall structure and framework for Part I-A of the Polar Code, as well as additional definitions not noted in the introduction, requirements for the issuance of Polar Ship Certificates and surveys, and the general criteria for determining ship performance standards and operational assessments. Where they exist, definitions of terms shared between this chapter and those within the Canadian regime prior to incorporation are largely similar or equal to one another. This chapter also requires that a Polar Ship Certificate reference a methodology to assess operational capabilities and limitations of a ship in ice. Under Canada's longstanding regime, the Zone/Date System (ZDS) and the Arctic Ice Regime Shipping System (AIRSS) are examples of this methodology.

\subsubsection{Polar Water Operational Manual}

Chapter 2 describes content to be included in the Polar Water Operational Manual (PWOM), a mandatory ship-specific document designed to support decision-making through the identification of procedures for operations under routine and emergency conditions. Prior to incorporation, no direct PWOM equivalent was required under the Canadian regime, although the PWOM must contain references to methodologies used to determine operational capabilities and limitations of a ship in ice (e.g., AIRSS). 


\subsubsection{Ship Structure}

Chapter 3 includes provisions to ensure that the materials and scantlings of ships with or without ice strengthening retain their structural integrity under certain environmental loads and conditions. This chapter seeks to provide assurance that a ship's structure is suitable for the environmental conditions by requiring that design plans be made to a recognized standard, such as Polar Class or the Finnish-Swedish (Baltic) Class, and that all materials be suitable if the ship intends to operate at low air temperatures. The contents of this chapter are generally equivalent to measures contained in the Canadian regime prior to incorporation.

\subsubsection{Subdivision and Stability}

Chapter 4 identifies requirements for ensuring adequate subdivision and stability for both damaged and intact ships at risk of ice accretion or ice-related damage. Provisions contained in this chapter are generally similar to those in the Canadian regime prior to incorporation.

\subsubsection{Watertight and Weathertight Integrity}

Chapter 5 contains requirements to maintain the watertight and weathertight integrity of all closing appliances and doors on board a ship. Prior to incorporation of the Polar Code, the Canadian regime had few specific requirements to address the maintenance of watertight and weathertight integrity of certain spaces on board ships operating in the Arctic.

\subsubsection{Machinery Installations}

Chapter 6 identifies requirements for ensuring that the machinery installations used on board ships operating in polar regions are capable of functioning under low air temperatures and in anticipated environmental conditions. Provisions contained in this chapter are generally broader and less prescriptive than related provisions in the Canadian regime prior to incorporation.

\subsubsection{Fire Safety/Protection}

Chapter 7 includes measures to ensure that fire safety systems and appliances are effective and operable, and that means of escape remain available under expected environmental conditions and at low air temperatures. Fire safety and protection requirements for ships operating under the Canadian regime are described in the 
Vessel Fire Safety Regulations and are generally equivalent, though less tailored to Arctic operations than requirements made under the Polar Code.

\subsubsection{Life-Saving Appliances and Arrangements}

Chapter 8 contains requirements that provide for safe escape, evacuation, and survival under various operating conditions. The Canadian regime prior to incorporation had no specific provisions for lifesaving appliances and arrangements unique to Canadian Arctic operations.

\subsubsection{Safety of Navigation}

Chapter 9 sets out measures for safe navigation, including with respect to ships involved in icebreaker escort operations, and requires the addition of certain navigation safety equipment. The Canadian regime had previously required that navigation safety equipment be present when operating in certain shipping safety control zones depending on the size of the ship. Polar Code measures still require additional navigation safety equipment for certain ships, though requirements for this equipment are less prescriptive (e.g., the option of one echo sounding device with two separate independent transducers) than previously contained in Canada's regime.

\subsubsection{Communications}

Chapter 10 sets out regulations for effective communications for ships and survival craft during normal and emergency situations. This chapter's contents are generally equivalent to the Canadian communication regime for ships operating in the Arctic prior to incorporation, though more explicit requirements for search and rescue (SAR) and telemedical assistance communications are included.

\subsubsection{Voyage Planning}

Unlike previous chapters, Chapter 11 does not include specific regulations that must be met. Instead, this chapter contains only requirements designed to ensure that the company, master, and crew are provided with sufficient information to enable operations to be conducted with due consideration for the safety of ships, persons on board, and awareness of local environmental conditions. With the exception of the requirement for a PWOM, all the contents of this chapter are generally equivalent to those contained within a variety of Canadian government publications (e.g., Notices to Mariners, Ice Navigation in Canadian Waters) prior to incorporation. 


\subsubsection{Manning and Training}

Chapter 12 includes provisions to help ensure that ships operating in polar waters are crewed by qualified, trained, and experienced personnel. While regulations concerning manning and training are noted in this chapter, the details-including various transitional provisions-are ultimately made pursuant to amendments to Chapter V of the International Convention on Standards of Training, Certification and Watchkeeping for Seafarers (STCW), 1978, as amended (IMO 2016a).

Similar in concept to that of a Canadian ice navigator, the Polar Code recognizes a person, other than a ship's officer, who is suitably qualified and experienced to operate in Arctic (or Antarctic) areas. Overall, provisions contained within this chapter are generally higher than those in the Canadian regime prior to incorporation, including additional training and qualifications requirements for certain personnel on board ships operating in open water (e.g., less than 1/10th ice concentration).

\subsubsection{Canadian Additions}

Certain provisions of Part 1 of the ASSPPR are not contained in the Polar Code, though are included in order to maintain as closely as possible key features of Canada's Arctic shipping regime prior to incorporation. In wanting to reflect consistency of application with other Canadian Arctic regulations (e.g., NORDREG), these additions are applicable in Canadian Arctic waters only and generally apply to all ships $300 \mathrm{GT}$ or more (including fishing vessels and pleasure craft), all ships engaged in towing or pushing another ship (if combined weight is $500 \mathrm{GT}$ or more), and all ships carrying a pollutant or dangerous good as cargo.

Ships that fit within the above criteria are required to follow one of two methodologies to assess operational capabilities and limitations in ice when operating outside prescribed periods in a shipping safety control zone: either AIRSS or the Polar Operational Limit Assessment Risk Indexing System (POLARIS) (IMO 2016b). Specifically, if the ship in question is of Polar Class or built after 1 January 2017, POLARIS must be used. The implied preference for POLARIS use under the ASSPPR rests on it being the more current and global of the two methodologies, as well as it having a built-in review period of 4 years set by the IMO to evaluate its efficacy.

The ASSPPR continues to require the presence of an ice navigator on board ships above 300 GT not certified in accordance with SOLAS. An ice navigator is a qualified master or deck watch officer who has served in this capacity on board a ship for a minimum of 50 days, 30 of which are to be in ice-infested Arctic waters.

Finally, Canadian ships built after 1 January 2017 must also be assigned a specific low air temperature notation in addition to the Polar Service Temperature. This notation is to ensure that systems and equipment not covered by the Polar Code or other IMO instruments remain functional at this temperature (e.g., deck machinery, hydraulic systems). 


\subsection{Pollution Prevention Measures}

The pollution prevention provisions of the ASSPPR were developed with an understanding that, under the AWPPA, a complete prohibition on the discharge of waste from ships exists except when authorized by regulations. Therefore, the ASSPPR assume this complete prohibition as a baseline and only introduce select operational and structural pollution prevention measures as found in Part II-A of the Polar Code, rather than fully incorporate by reference. Unless provided otherwise, Part 2 of the ASSPPR is applicable to all ships operating in Canadian Arctic waters and all Canadian ships operating in polar waters.

\subsubsection{Prevention of Pollution by Oil}

Concerning the prevention of pollution by oil, the Polar Code sets out both operational and structural requirements. Operationally, all discharges into the water column of oil or oily mixtures are completely prohibited, essentially aligning Arctic standards with measures already in place in the Antarctic area (after its designation as a Special Area under MARPOL Annex I on 16 November 1990), and thereby prohibiting even the trace amounts of discharge (e.g., $15 \mathrm{ppm}$ ) permitted under the MARPOL Convention.

Structurally, all ships built on or after 1 January 2017 that have been designed for operations in thin to medium first-year ice, and with an aggregate oil fuel capacity of less than $600 \mathrm{~m}^{3}$, require the separation of oil fuel tanks, oil cargo tanks, and sludge tanks from the outer shell. In addition, smaller oil tankers of less than 5000 tonnes, built on or after 1 January 2017, and also having been designed for operations in thin to medium first-year ice, require cargo tanks to be constructed with added protection, including double bottom tanks. In doing so, the structural provisions currently applicable under MARPOL Annex I to larger ships are essentially extended down to ships of all sizes operating within the polar regions.

Maintaining Canada's prohibition on the discharge of oil in Canadian Arctic waters therefore required prohibiting Polar Code allowances for the discharge of clean ballast (that may contain up to 5 ppm of oil) and the discharge of oily water from machinery spaces of Category A ships operating for more than 30 days in the Arctic.

\subsubsection{Control of Pollution by Noxious Liquid Substances in Bulk}

Under MARPOL Annex II, ships (e.g., chemical tankers) are permitted the controlled discharge of certain noxious liquid substance (NLS) residues, as well as the discharge of ballast water or tank washings that contain NLS. The Polar Code, 
however, completely prohibits these discharges, though in the Arctic region only, as regulations already exist prohibiting similar discharges in the Antarctic area (pursuant to its designation as a Special Area under MARPOL Annex II on 30 October 1992).

In addition, under section 2.1.2.3 of the International Code for the Construction and Equipment of Ships Carrying Dangerous Chemicals in Bulk (IBC Code), ships built on or after 1 January 2017 designed for operations in thin to medium first-year ice that carry NLS deemed to have "sufficiently severe" environmental and safety hazards now require approval by their flag state administration to carry these substances. "Sufficiently severe" is third in rank in the IBC Code behind "severe" and "appreciably severe," and unlike these other two categories is not subject to prescribed location requirements for cargo tanks. Accordingly, the goal of this provision is to limit the carriage of NLS against the side shell of ships operating in polar regions by requiring extra discretion through flag state approval.

As the AWPPA already prohibits the discharge of NLS, the ASSPPR does not duplicate this Polar Code prohibition. However, the remaining operational requirements contained within the Polar Code with respect to modifying ship documentation (e.g., Cargo Record Books and Manuals) are incorporated in the ASSPPR.

\subsubsection{Prevention of Pollution by Sewage from Vessels}

The Polar Code sets out operational requirements allowing for the release of sewage only when done in accordance with specific provisions, including at a range of specified distances based upon whether or not the sewage has been ground and disinfected. Whereas MARPOL Annex IV establishes discharge distances from land, the Polar Code's primary difference here is that it also considers discharges from the ice shelf, fast ice, and areas exceeding 1/10th ice concentration.

For ships operating with an approved sewage treatment plant, discharge distances set out under the Polar Code are less prescriptive, though they must still occur as far as practicable from the ice shelf, fast ice, and areas exceeding 1/10th ice concentration. Indeed, all ships designed for operations in thin to medium first-year ice and all passenger ships constructed on or after 1 January 2017 must have an approved sewage treatment plant on board; otherwise sewage is to be retained. These new rules are similar to those currently applicable under MARPOL Annex IV, Regulation 11, paragraph 3, which prohibits the discharge of sewage from passenger ships operating in Special Areas except if using an approved sewage treatment plant certified by the Administration, and provided that the effluent does not produce visible floating solids or cause discoloration of the surrounding water.

The AWPPA and the ASPPR previously allowed for the release of untreated sewage into Canadian Arctic waters (AWPPA 1970; ASPPR 2006). Recognizing the advancements in sewage treatment technology, the ASSPPR replace this allowance with the Polar Code's requirement for the discharge of treated sewage from ships 400 GT or more or certified to carry more than 15 persons. Additionally, the ASSPPR incorporate modified versions of the Polar Code's various other 
operational discharge requirements not currently included within the Canadian regime, including minimum discharge distances from ice. For ships not subject to MARPOL Annex IV though more than 15 GT but less than 400 GT, the discharge of sewage will be subject to certain distance and speed considerations. For ships of not more than $15 \mathrm{GT}$, untreated sewage will remain permitted.

\subsubsection{Prevention of Pollution by Garbage from Vessels}

The disposal of garbage generated on board ships is also addressed by the Polar Code. As MARPOL Annex V already covers the Antarctic area and sets out strict discharge provisions, the Polar Code's regulations on garbage are primarily limited to the Arctic region, thereby making it a de facto Special Area. Therefore, in both the Arctic and Antarctic, the discharge of garbage (including animal carcasses) is prohibited with the exception of food wastes, provided such wastes are ground and comminuted, and disposed of at set distances from land and ice. Regardless of area of operation, MARPOL Annex V, Regulation 3, already prohibits the disposal of all plastics within the water column, including synthetic ropes, synthetic fishing nets, plastic garbage bags, and incinerator ashes from plastic products.

Only certain operational requirements contained in the Polar Code pertaining to garbage are incorporated into the ASSPPR. As with other discharges, the AWPPA prohibits the release of waste except as provided by regulations. Accordingly, the Polar Code's allowances for the discharge of cargo residues, while subject to certain conditions, nevertheless remain prohibited under the ASSPPR. For ships operating in Canadian Arctic waters, only food waste subject to certain criteria (e.g., comminuted or ground) is permitted to be discharged and, similar to sewage discharge requirements, is also subject to minimum distances from ice.

\subsection{Consequential Amendments}

To avoid conflict, duplication, and to reflect internationally agreed upon standards, a variety of consequential amendments were made to several other regulations upon entry into force of the ASSPPR. In addition to repealing the Arctic Shipping Pollution Prevention Regulations, sections of both the Navigation Safety Regulations (2005) and Ship Station (Radio) Regulations, 1999 (2000) pertaining to additional navigation safety equipment while operating within Arctic shipping safety control zones were also removed in lieu of those requirements identified within the Polar Code. Further, modifications to sections of the Vessel Pollution and Dangerous Chemical Regulations (VPDCR 2012) were made to remove any conflict with the pollution prevention measures contained within the ASSPPR. 


\subsection{Regulatory Publication}

The ASSPPR were published in Part I of the Canada Gazette on 1 July 2017 (Government of Canada 2017) and were accompanied by a 75-day comment period. During this time, comments from 10 separate stakeholders were received. These comments generally included requests for the inclusion of additional content considered to be outside the scope of the regulations (e.g., a ban on heavy fuel oil use by ships in the Arctic) and requests for clarity of interpretation.

A consequence of the ASSPPR's primary focus on incorporation of the Polar Code is that the regulations are non-exhaustive in their treatment of other environmental concerns facing the Arctic, including many raised by stakeholders that remain unaddressed at both the domestic and international levels. However, their omission does not reflect their level of importance, nor does it preclude the possibility of them being addressed within Canada's Arctic shipping regime at a later date. Rather, as these issues would have required further consideration and consultation that could have delayed the domestic implementation of the Polar Code, Canada made the decision to address them separately.

Overall, no objections to the regulations were received and no substantive changes were made as a result of stakeholder input. Only minor amendments for purposes of added clarity were introduced. The ASSPPR were then published in Part II of the Canada Gazette (Government of Canada 2018) and registered on 19 December 2017, thereby meeting the delayed entry into force window set at 1 January 2018.

Accordingly, on 8 February 2018, the High Commission of Canada in London advised the Secretary-General of the IMO that with respect to MARPOL amendments, Canada had completed its national procedural requirements for bringing them into force. In doing so, Canada approved, under Article 16(2)(f)(ii) of MARPOL, the entry into force of these amendments. With respect to SOLAS, Canada's view was that in accordance with Article VIII(b)(vii)(2) of SOLAS, these amendments automatically entered into force on 1 January 2018, and that no additional express notification was required.

\subsection{Conclusion}

Inasmuch as the Polar Code marked a sea change in the international order for ships operating in the Arctic and Antarctic, its adoption and entry into force did not bring to a conclusion discussions on how to further reduce risk or fully confront the unique hazards ships encounter in these regions. Indeed, the comments received during regulatory pre-publication of the ASSPPR provide evidence of this. Further, for all its deserved praise in effectively replacing the otherwise inconsistent regulatory environment for ships transiting high latitudes, the Polar Code's less prescriptive goal-based approach to standard setting for safety measures (representative of a new direction within the IMO) has resulted in certain open interpretations. 
To address this, the IMO Sub-Committee on Ship Systems and Equipment (SSE) has developed Interim Guidelines on Life-Saving Appliances and Arrangements for Ships Operating in Polar Waters (IMO 2019a) in an effort to further mitigate polar hazards and to facilitate compliance with Chapter 8 (Life-Saving Appliances and Arrangements) of the Polar Code. Meanwhile, the IMO Sub-Committee on Navigation, Communications and Search and Rescue (NCSR) also developed Guidance for Navigation and Communication Equipment Intended for Use on Ships Operating in Polar Waters (IMO 2019b) that provide recommendations on general requirements as well as specific performance standards.

In parallel to these efforts, the IMO's MSC is considering the extent to which additional safety measures related to navigation safety and voyage planning should be made mandatory for non-SOLAS ships operating in polar waters. Complementary Guidelines for Safety Measures for Fishing Vessels 24 Meters and Over Operating in Polar Waters and Guidelines for Safety Measures for Pleasure Yachts of 300 GT and Above not Engaged in Trade Operating in Polar Waters (IMO 2018) are also in the process of being developed at the request of MSC by the IMO's Sub-Committee on Ship Design and Construction.

Efforts to provide further regulatory clarity concerning polar ship operations are not restricted to the IMO. Indeed, since the entry into force of the ASSPPR, Canada has updated or developed a range of new bulletins, guidelines, and standards, all of which are intended to facilitate the implementation and harmonized interpretation of the Polar Code in Canada. For example, the Arctic Ice Regime Shipping System Standard (Transport Canada 2018) has been updated to reflect the use of POLARIS as an official methodology for ships to assess operational capabilities and limitations in ice. Additionally, the AIRSS Pictorial Guide (Transport Canada 2003) and User Assistance Package (Transport Canada 1998) have both been replaced in lieu of the more comprehensive Guidelines for Assessing Ice Operational Risk (Transport Canada 2019) which describe, in practical terms, the application of parts of the ASSPPR and other regulations relevant to reducing the risks for vessels navigating in Arctic waters under Canadian jurisdiction.

The Polar Code remains a comparatively new international instrument and as such continues to contend with a paucity of experience in application. The same is also true of the ASSPPR. Aided by various clarification and guidance material, invaluable practical experience will accumulate over time to further inform interpretations, providing the needed justification for regulatory fixes or improvements to the safety and pollution prevention standards of both regimes.

\section{References}

ASPPR. (2006). Arctic Shipping Pollution Prevention Regulations, CRC, c 353 (Repealed) (Canada).

ASSPPR. (2017). Arctic Shipping Safety and Pollution Prevention Regulations, SOR/2017-286 (Canada). 
AWPPA. (1970). Arctic Waters Pollution Prevention Act, RSC 1985, c A-12 (Canada).

Government of Canada. (2017). Arctic Shipping Safety and Pollution Prevention Regulations: Regulatory impact analysis statement, Canada Gazette: Part 1., 151(26), 2867-2908.

Government of Canada. (2018). Registration SOR/2017-286 (19 December 2017): Arctic Shipping Safety and Pollution Prevention Regulations, Canada Gazette: Part II., 152(1), 15-61.

IMO (International Maritime Organization). (1992). Accession by Canada to the Protocol of 1978 Relating to the International Convention for the Prevention of Pollution from Ships, 1973, IMO Doc. PMP/Circ. 105 (7 December).

IMO. (2016a). Annex 8 - Resolution MSC.416(97) Amendments to the International Convention on Standards of Training, Certification and Watchkeeping for Seafarers (STCW), 1978, as amended (adopted 25 November 2016), IMO Doc. MSC 97/22/Add.1 (6 December).

IMO. (2016b). Guidance on methodologies for assessing operational capabilities and limitations in ice, IMO Doc. MSC.1/Circ.1519 (6 June).

IMO. (2018). Report of the Maritime Safety Committee on its ninety-ninth session, IMO Doc. MSC 99/22 (5 June).

IMO. (2019a). Interim Guidelines on Life-Saving Appliances and Arrangements for Ships Operating in Polar Waters, IMO Doc. MSC.1/Circ.1614 (26 June).

IMO. (2019b). Guidance for navigation and communication equipment intended for use on ships operating in polar waters, IMO Doc. MSC.1/Circ.1612 (14 June).

MARPOL. (1973/78). International Convention for the Prevention of Pollution from Ships (adopted 2 November 1973), 1340 UNTS 184, as amended by the Protocol of 1978 Relating to the International Convention for the Prevention of Pollution from Ships (adopted on 17 February 1978, entry into force 2 October 1983), 1340 UNTS 61.

Navigation Safety Regulations, SOR/2005-134 (Canada).

NORDREG. (2010). Northern Canada Vessel Traffic Services Zone Regulations, SOR/2010-127.

Polar Code. (2014/2015). International Code for Ships Operating in Polar Waters (Polar Code), IMO Resolution MSC.385(94) (21 November 2014, effective 1 January 2017); Amendments to the International Convention for the Safety of Life at Sea 1974, IMO Resolution MSC.386(94) (21 November 2014, effective 1 January 2017); Amendments to MARPOL Annexes I, II, IV and V, IMO Resolution MEPC.265(68) (15 May 2015, effective 1 January 2017). http://www. imo.org/en/MediaCentre/HotTopics/polar/Documents/POLAR\%20CODE\%20TEXT\%20 AS\%20ADOPTED.pdf. Accessed 17 Oct 2019.

Ship Station (Radio) Regulations, 1999, SOR/2000-260 (Canada).

SOLAS. (1974). International Convention for the Safety of Life at Sea, 1974 (adopted 1 November 1974, entry into force 25 May 1980), as amended, 1184 UNTS 2.

Transport Canada. (1998). User Assistance Package for the Implementation of Canada's Arctic Ice Regime Shipping System (AIRSS). TP 12819. Repealed.

Transport Canada. (2003). Arctic Ice Regime Shipping System Pictorial Guide. TP 14044. Repealed.

Transport Canada. (2018). Arctic Ice Regime Shipping System (AIRSS) Standard. TP 12259.

Transport Canada. (2019). Guidelines for assessing ice operational risk. TP 15383.

UNCLOS. (1982). United Nations Convention on the Law of the Sea (10 December 1982, entered into force 16 November 1994), 1833 UNTS 396.

VPDCR. (2012). Vessel Pollution and Dangerous Chemical Regulations, SOR/2012-69 (Canada). 
Open Access This chapter is licensed under the terms of the Creative Commons Attribution 4.0 International License (http://creativecommons.org/licenses/by/4.0/), which permits use, sharing, adaptation, distribution and reproduction in any medium or format, as long as you give appropriate credit to the original author(s) and the source, provide a link to the Creative Commons license and indicate if changes were made.

The images or other third party material in this chapter are included in the chapter's Creative Commons license, unless indicated otherwise in a credit line to the material. If material is not included in the chapter's Creative Commons license and your intended use is not permitted by statutory regulation or exceeds the permitted use, you will need to obtain permission directly from the copyright holder. 